\title{
Cindy Sherman y la subversión de la identidad
}

\section{Cindy Sherman and the Subversion of Identity}

\author{
Soledad Prieto Millán \\ Facultad de Humanidades, Universidad de Chile. Santiago, Chile. \\ soleprietom@gmail.com
}

\section{Resumen}

El análisis crítico del concepto de identidad inviste implicancias para los estudios de género, más concretamente, la posibilidad de fragmentar la noción de una identidad inamovible y metafísica de los sujetos sexuados. Este artículo analiza cómo la identidad de género puede ser construida y reconstruida a partir de diversas culturas, momentos históricos, dispositivos simbólicos y discursos de poder. Para ello, se abordarán algunas conceptualizaciones sobre la identificación en la obra de Sigmund Freud y Jacques Lacan, y se realizará un análisis de los conceptos de performatividad y de parodia del género de Judith Butler, para luego dialogar con el concepto de pastiche desarrollado por Fredric Jameson. Se utilizará como soporte algunas fotografías de la obra Centerfolds de la artista norteamericana Cindy Sherman.

Palabras clave: Identidad de género, performatividad, imagen, psicoanálisis, pastiche.

\begin{abstract}
The critical analysis of the concept of identity has marked implications for gender studies, specifically in relation to fragmenting the notion of static and metaphysical identity of sexualized subjects. This paper analyzes how gender identity can be constructed and reconstructed based on culture, periods in history, symbolism and the discourse of power. To this end, this article will discuss various concepts of gender identity described in the work of Sigmund Freud and Jacques Lacan, as well as the concepts of performativity and gender parody developed by Judith Butler. Finally, the concept of pastiche, developed by Fredric Jameson, will be discussed. Photographs of Cindy Sherman's Centerfolds will be used as support.
\end{abstract}

Keywords: Gender identity, Performativity, Image, Psychoanalysis, Pastiche. 
...la imagen es aquello de lo que estoy excluido.

R. Barthes, Fragmentos de un discurso amoroso

\section{Introducción}

En el contexto de los estudios de género, las nociones de identidad de género y de heteronormatividad se problematizan y se ponen en cuestión a partir de una ruptura con las propuestas que han defendido una ontologización de los sujetos; así, las categorías de "identidad" y de "género" ya no son posibles de concebir "como algo que se cierra linealmente sobre un núcleo garantizado de atributos predeterminados" (Richard 63). Para este proyecto, han sido fundamentales los diálogos con el psicoanálisis, el estructuralismo y la filosofía deconstructiva, al tomar en consideración sus postulados sobre la descentralización del sujeto a partir de la noción de inconsciente y de identificación, la ruptura con la tradición metafísica de oposiciones binarias que configuran la identidad en categorías absolutas y opuestas, y el valor que se le otorga al sistema simbólico como formulador de sentido que rebate el esencialismo sexual. Estos postulados constituyen la base para la crítica feminista actual, los estudios de género y la teoría queer, y para la referente ineludible de este movimiento, Judith Butler.

El concepto de performatividad propuesto por Butler se nutre de los discursos antes mencionados proponiendo la realización performativa del género y de la materialidad de los cuerpos, y supone a la identidad como una construcción que generaría una apariencia de sustancia, la que sería preservada por los discursos hegemónicos con la finalidad de regular los cuerpos y los géneros dentro del marco de la heteronormatividad. La noción de parodia del género, en tanto, constituye una propuesta subversiva interesante que la autora reconoce en expresiones tales como el travestismo y las identidades butch/femme, la que sería posible asimilar -y a la vez diferenciar- de la noción de pastiche elaborada por Fredric Jameson. Se intentará realizar una revisión de estos postulados y argumentar de qué manera contribuyen a los estudios de género por medio de una desestabilización del concepto de identidad de género. En este artículo se utilizará la obra Centerfolds de la artista contemporánea Cindy Sherman como medio para facilitar el análisis de los conceptos de performatividad y pastiche; concretamente, se planteará que aquella constituye una puesta en escena de estereotipos de género de la mujer, a la vez que expone una narrativa visual descentralizadora de la identidad.

\section{Discursos descentralizadores}

Los discursos filosóficos y psicológicos que a lo largo de la historia se han dedicado al estudio de la subjetivación se han apuntalado en la concepción etimológica del término identidad, insistiendo en el sentido de individualidad e inmutabilidad del 
uno(a) mismo(a) ${ }^{1}$. Esta concepción revela el carácter metafísico que se le otorga, en el sentido de concebir un ser preexistente al lenguaje, dando cuenta de una idea del sí mismo en tanto esencia. La forma matriz de la metafísica consistiría en lo que Jacques Derrida define como "la determinación del ser como presencia" (385), matriz que promueve una concepción del sujeto como un "individuo" que es portador de una esencia inmutable y anterior a toda influencia del medio.

A fines del siglo xIx y principios del siglo xx, Sigmund Freud formula una concepción de la identidad que constituye un salto epistemológico en relación a los discursos hegemónicos previos y de aquel entonces. La conceptualización de lo inconsciente y la elaboración de los procesos de identificación resiste a un proyecto que lleva como referente la voluntad de la consciencia y de la identidad, generando la noción de un sujeto descentralizado respecto de sí mismo y que iría construyendo su identidad desde las diversas identificaciones con sus objetos de amor. En el texto "Algunas consecuencias psíquicas de las diferencias anatómicas entre los sexos", Freud da cuenta de la manera en que a partir de estas diversas identificaciones y de los meandros cursados en el complejo de Edipo, se obtendría la consistencia del "yo", así como la identidad de "mujer" y de "hombre", proceso psíquico que no estaría completamente determinado por el sexo anatómico.

Posteriormente, Jacques Lacan, con su retorno a Freud e influenciado por la filosofía, el estructuralismo y la lingüística estructural de Ferdinand de Saussure, inaugura una nueva conceptualización del sujeto. En este caso, se trata de un sujeto articulado como sujeto de deseo determinado desde el deseo del Otro, que es producto de los efectos del inconsciente estructurado como un lenguaje. En los inicios de su obra ${ }^{2}$ comienza a utilizar como dispositivo explicativo la dialéctica del espejo, con el objetivo de complementar el proceso del complejo de Edipo e ilustrar cómo el yo del sujeto es constituido desde un afuera por medio de la conquista imaginaria de la unidad del propio cuerpo. En su texto "El estadio del espejo como formador de la función del yo (Je) tal como se nos revela en la experiencia psicoanalítica”, relata cómo el cuerpo sería siempre fragmentado, y anticiparía su unidad en la imagen ilusoria y enajenante. De ahí que el yo sea una matriz de identificaciones: "El estadio del espejo es un drama cuyo empuje interno se precipita de la insuficiencia a la anticipación; y que para el sujeto, presa de la ilusión de la identificación espacial, maquina las fantasías que se sucederán desde una imagen fragmentada del cuerpo hasta una forma que llamaremos ortopédica de su totalidad" (90).

1 El concepto de identidad proviene del latín "identĭtas, -ātis", que a su vez deriva de "ídem", que significa "el mismo", "lo mismo" (RAE). Ferrater expone que el concepto de identidad ha sido examinado desde varios puntos de vista; entre estos, el ontológico es uno de los más destacados, "según el cual toda cosa es igual a ella misma" (175).

2 Antes de la exposición en Zúrich en el año 1949, Jacques Lacan presentó la dialéctica del espejo en el xiv Congreso Psicoanalítico Internacional en Marienbad el 16 de Junio de 1936, exposición de la que no existe registro. Sin embargo, es posible acceder a los apuntes tomados por la psicoanalista oyente Françoise Dolto. Véase Guillerault, Gérard. Le miroir et la psyché: Dolto, Lacan et le stade du miroir. Paris: Gallimard, 2003. Agradecemos esta información al psicoanalista Jorge Baños Orellana, quien la compartió en su grupo de estudios Lecturas Cronológicas de Lacan. 
Desde la filosofía posestructural, Judith Butler revisita algunos referentes del psicoanálisis, del feminismo y de la filosofía, en especial a Michel Foucault y su énfasis en la categoría de sexo como históricamente construido, siendo más bien efecto que causa de subjetivación. Para llevar a cabo su proyecto feminista de desnaturalizar la identidad de género y realizar "una genealogía feminista de la categoría de las mujeres" (Butler, El género 53), en su importante libro El género en disputa, incrementa y extrapola el proyecto deconstructivo de la identidad, enfatizando que tanto la identidad de género como el cuerpo sexuado serían construcciones determinadas por discursos de poder que definirían los cuerpos y los roles de género, produciendo la heterosexualidad normativa. La filósofa expone que las diversas identificaciones que constituyen al sujeto se manifestarían en actos, palabras y deseos que generarían el efecto ilusorio de un núcleo interno y que se caracterizarían por ser "performativos, en el sentido de que la esencia o la identidad que pretenden afirmar son invenciones fabricadas y preservadas mediantes signos corpóreos y otros medios discursivos" (Butler, El género 266). Este efecto ilusorio de núcleo interno designaría una unidad de experiencia, de acuerdo a la cual se presupondría una relación causal entre sexo, género y deseo, relación que generaría una ficción de continuidad en la que el deseo sería reflejo del género y el género reflejo del sexo.

El concepto de parodia del género le permite a Butler demostrar cómo las prácticas del travestismo y las identidades lesbianas butch/femme tienen un efecto subversivo, dado que "al imitar el género, la travestida manifiesta de forma implícita la estructura imitativa del género en sí, así como su contingencia” (269). El efecto subversivo se generaría por medio de una disonancia entre la anatomía del actor y el género que se actúa, en un gesto de imitación y de desmontaje corporal que desnaturaliza al sexo y al género, a la vez que desafía la ley de coherencia heterosexual. Para Butler, el travestismo cumpliría una función subversiva exclusivamente en algunas ocasiones, dado que "la heterosexualidad puede argumentar su hegemonía a través de su desnaturalización, como cuando vemos esas parodias de desnaturalización que reidealizan las normas heterosexuales sin cuestionarlas" (Cuerpos que importan 325). Butler aclara que la noción de parodia que ella propone no supone la presencia de un original al que se imita, dado que la parodia se daría sobre la misma existencia de ese original; sin embargo, agrega que, según los postulados de Fredric Jameson, la noción que se burla del concepto de un original sería más propia del pastiche, un término que nos acerca al terreno del arte posmoderno y que consideramos que tendría mayor relación con el efecto subversivo del trabajo de Cindy Sherman.

Las posibilidades transgresivas de prácticas del travestismo, de los cuerpos transgénero y transexuales son retomadas por Beatriz Preciado (ahora llamado Paul B. Preciado) atendiendo a la materialidad y a la inscripción sobre los cuerpos. Son aspectos que, según ella, Butler no habría acentuado: Butler "habría ignorado los procesos corporales y especialmente las transformaciones que suceden en los cuerpos transgénero y transexuales, así como las técnicas de estabilización del género y del 
sexo que operan en los cuerpos heterosexuales" (Manifiesto 75). Preciado se interesa por las "transformaciones físicas, sexuales, sociales y políticas de los cuerpos" (75) que devienen en los transgénero y los transexuales, más que por el aspecto teatral e imitativo de la performance, preguntándose por "los efectos de trasformación de la carne implicados en toda invocación performativa de la identidad sexual" (77). Rompe con la histórica dicotomía esencialismo/constructivismo y considera los postulados de Donna Haraway para pensar el sexo en tanto tecnología, a propósito de la invasión de los cuerpos por la biotecnología. Nos interesa especialmente su propuesta del estatuto borderline de la prótesis para graficar la imposibilidad de distinción entre lo natural y lo artificial, y su exposición del punto de vista de Marshall McLuhan sobre las tecnologías del siglo xx como "suplementos prostéticos de una función natural" (Preciado, Manifiesto 132), aspecto que nos permitirá otorgarle a la cámara fotográfica el estatuto de prótesis de la vista.

\section{Escenificaciones performativas}

La artista norteamericana Cynthia Morris Sherman, más conocida como Cindy Sherman, es una fotógrafa que subvierte el lugar de observador del fotógrafo y se sitúa al lado inverso del lente de la cámara, utilizando su propio cuerpo como soporte para representar diversos estereotipos de mujeres que han sido creados, exhibidos y potenciados por los mass media. Se convierte, de esta manera, en heroína de películas clásicas, en una modelo de portada de revista masculina, venus y musa de pintores clásicos y en una mujer de clase alta de Hollywood. En el ejercicio de su trabajo es posible identificar dos aspectos de interés para los estudios de la identidad y de género. En primer lugar, la producción de un relato visual que habilita una crítica de la concepción de una identidad fija e inmutable, debido al uso que hace de sí misma como soporte para representar un(a) otro(a). En el momento de la representación, escenifica por un instante su desaparición para personificar, diremos performativamente, estereotipos femeninos construidos discursivamente en la sociedad. Su lugar de sujeto es trasladado y reemplazado por la nueva identidad que encarna, aspecto al que se que refiere en algunas de sus entrevistas ${ }^{3}$ : "Cuando veo las fotografías, nunca me veo a mí misma; no son autorretratos. Algunas veces desaparezco"4 (Sherman "A portraitist's" párr. 1, el énfasis es nuestro). El segundo aspecto de interés es el desmontaje que las personificaciones de Sherman efectúan sobre los estereotipos femeninos construidos por los mass media contemporáneos en Estados Unidos, siendo un manifiesto visual del carácter ficcional de estos.

3 Dado que las entrevistas y algunos textos citados a continuación no han sido traducidos al español, en lo sucesivo se procederá a realizar una traducción libre.

4 "When I look at the pictures, I never see mi self; they aren't self-portraits. Sometimes I disappear". 
En el año 1981 presenta la obra Centerfolds, la que originariamente consistió en un proyecto de fotografías en extensión de dos páginas encargado por la revista Artforum, en el que la artista, inspirada en las páginas centrales de revistas pornográficas, personificó diversas personajes imaginarias que se muestran erotizadas, pero a la vez atemorizadas e intranquilas debido a su posición de objeto de mirada para el goce escópico del otro. Estas imágenes constituyen un material de análisis y de deconstrucción a partir de los signos que presentan las mismas personajes, tales como el lenguaje gestual, postural y la mirada; así como desde la misma representación, el formato y la materialidad de la fotografía. En nuestra lectura, se tendrá como supuesto que el conjunto de estos signos se materializan formando una unidad imaginaria que daría cuenta de estereotipos femeninos presentes en la sociedad contemporánea. En este sentido, y adicionalmente, parece interesante abordar el lugar en el que es situado el supuesto observador de estas fotografías, dado que la artista pretende generar en el voyeur masculino responsabilidad y culpa por la posición de objeto en que es significada la mujer, lo que lo ubica en el lugar del abusador o violador: "Yo quise a un hombre abriendo la revista que repentinamente la mirara con una expectativa de algo lascivo y luego se sintiera como el violador que ellos deberían ser"5 (Sherman cit. en Burton 26). Sherman indaga en la manera como nosotros(as) nos situaríamos en ese mismo lugar de voyeur, confrontándonos con nuestro involucramiento en la perpetuación de estos estereotipos femeninos a través de la mirada, la aceptación y su propia representación.

Un análisis más detallado de su obra requiere contextualizarla en el lugar que ocupa dentro de la historia del arte, pues es parte del momento fundamental en que las producciones artísticas comienzan a involucrarse en el análisis crítico y feminista contemporáneo. Según la opinión de Hal Foster, el arte de los años sesenta se centraba en dos objetivos aparentemente opuestos: por un lado, en el logro de su autonomía; y por el otro, en la capacidad de sobrepasar esta misma para alcanzar el terreno de la cultura y de los mass media considerando los nuevos aportes sobre el valor del lenguaje. A partir de los años setenta se radicaliza este proyecto, invadiendo tanto la práctica como la teoría. Esta dialéctica se traduciría en dos versiones de las propuestas artísticas: la neoconservadora, por un lado, que potenciaría el retorno de una memoria cultural y de las representaciones históricas; y por otro, la posestructuralista, que se encargaría de realizar una crítica a las mismas categorías de representación y autoría. Esta última propuesta comienza un proyecto de desmaterialización del objeto artístico para despojarlo sus rasgos de unicidad y, a su vez, generar una nueva noción de obra a partir de una proliferación de materialidades, utilizando hasta las más inesperadas, tales como desechos, instrumentos de uso diario y cuerpos humanos (Jiménez). A partir de una crítica manifiesta de los conceptos de representación y de autoría, se

5 "I wanted a man opening up the magazine to suddenly look at it with an expectation of something lascivious and then feel like the violator that they would be". 
intensifica el diálogo con los mass media y la cultura popular, ya que el arte comienza a apropiarse de imágenes y estereotipos obtenidos de revistas publicitarias y de dramas televisivos y cinematográficos.

La versión posestructuralista de la posmodernidad “intentó rebasar tanto las categorías estéticas formales (el orden disciplinario de la pintura, la escultura, etc.) y las distinciones culturales tradicionales (la alta cultura frente a la de masas, el arte autónomo frente al utilitario), con un nuevo modelo de arte como texto" (Foster 76). La imagen creada, desde esta mirada, no tendría un significado propio y que se encuentre bajo el control del autor, sino que estaría determinada por la referencia a otras imágenes o signos (Cotton). La crítica feminista, dentro de esta segunda versión del arte que propone Hal Foster, se centra en el cuestionamiento de la concepción de una identidad prefijada y ontológica, e impulsa su deconstrucción al cuestionar los límites entre sexo y género, la heteronormatividad, el discurso falocéntrico y sus efectos imperialistas, los que estarían mediatizados y proliferados por los mass media y la publicidad. El cuerpo como una construcción socialmente determinada, despojado de lo supuestamente propio y prediscursivo, se virtualiza, se fragmenta, se utiliza y desontologiza en un happening, en una fotografía o en una performance.

Los primeros trabajos de Cindy Sherman utilizan la cultura popular como herramienta de trabajo sin emplear la teoría, y a pesar de que la artista no se identifica como feminista, su trabajo fue aceptado como tal, pues se consideró que no habría sido posible sin la reflexión crítica que se había estado formulando previa y contemporáneamente, y debido a que en su obra habría un cuestionamiento de la mujer que es perpetuada por los mass media y los estereotipos contemporáneos. Forma parte central de su trabajo el cuerpo de la mujer situado en los espacios públicos y divulgado por los medios de comunicación, así como en los espacios más íntimos como una habitación o una cama, donde la intimidad se muestra ofrecida a la mirada del otro, lo que resulta en una sugestiva puesta en juego de las dimensiones de lo privado y lo público. Laura Mulvey propone una interesante hipótesis al respecto: "Sherman disecciona el espacio fantasmagórico conjurado por el cuerpo de la mujer, desde su exterioridad hasta su interioridad"6 (135), ya que en sus primeros trabajos es posible delinear un desplazamiento en los espacios, desde la exterioridad del cuerpo situado en espacios públicos en Untitled Film Stills (1977-1980), pasando por el espacio emocional y situacional más íntimo de Centerfolds (1981) a la fragmentación y desublimación del cuerpo en Fairy Tales (1985), Disastres (1986-1989) y Sex Pictures (1992), donde se evidencia lo abyecto y residual del cuerpo dentro de la sociedad occidental falocéntrica y de consumo.

La obra Centerfolds constituye un espacio intermedio en este viaje virtual por la espacialidad de lo que es significado como femenino, al exhibir la emocionalidad y vulnerabilidad de aquella identificación, expuesta a la mirada invasiva del otro mas-

6 "Sherman dissects the phantasmagoric space conjured up by the female body, from its exteriority to its interiority". 


\section{FIGURA 1}

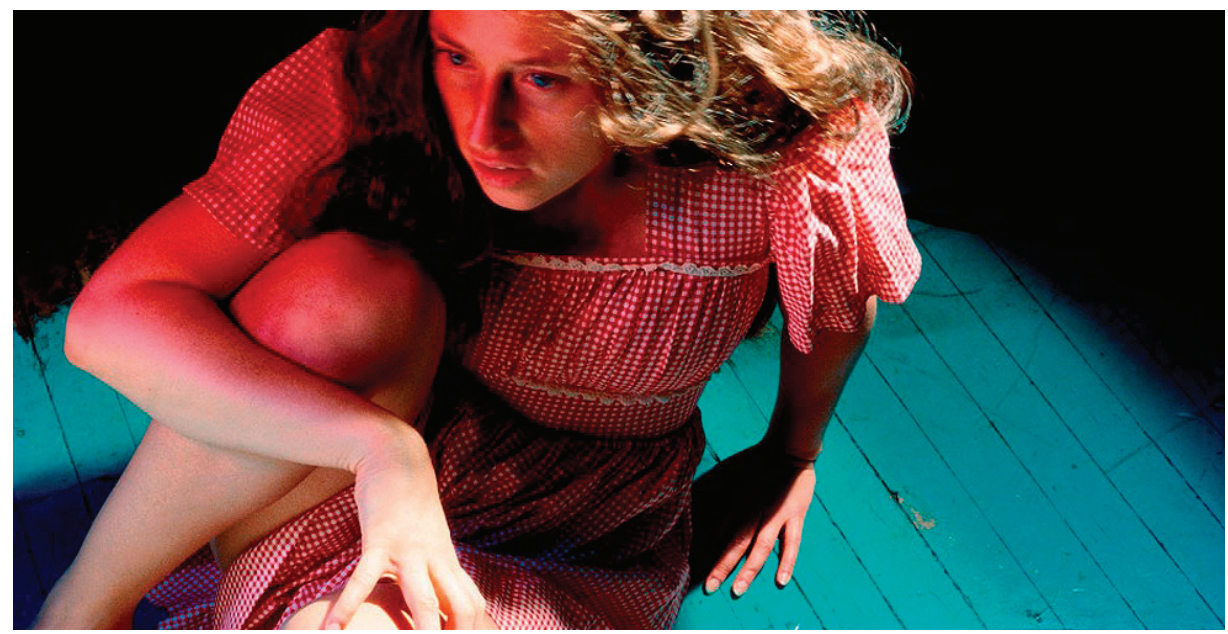

Untitled \# 85, Centerfolds, Cindy Sherman. Impresión cromogénica a color $61 \times 121.9 \mathrm{~cm} .1981$. Colección de Jean Pigozzi, Ginebra.

\section{FIGURA 2}

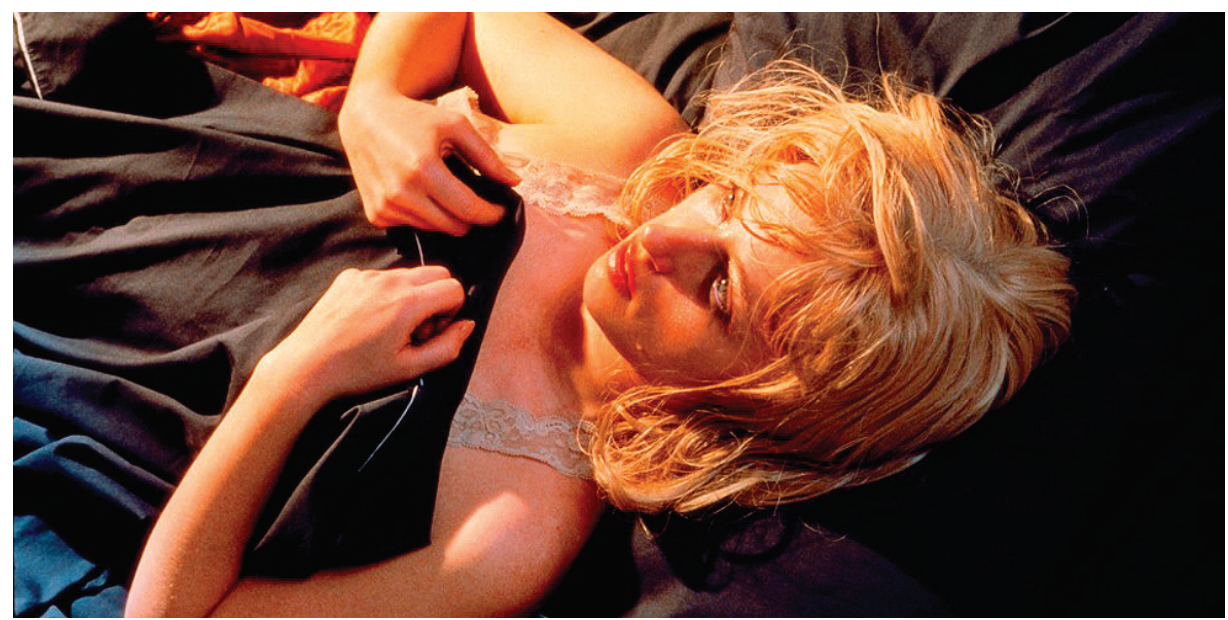

Untitled \# 93, Centerfolds, Cindy Sherman. Impresión cromogénica a color $61 \times 121.9 \mathrm{~cm}$. 1981. Colección de Marieluise Hessel, Hessel Museum of Art, Centre for Curatorial Studies, Bard College, New York.

culino. Se trata de una serie de fotografías en color con un espacio interior y privado como escenario en el que "la intimidad femenina es cuidadosamente coreografiada" (Preciado, Pornotopía 54). Todas las imágenes presentan el mismo formato horizontal extendido donde se ubican pasivamente las personajes que encarna la misma Cindy Sherman, sentadas o recostadas sobre suelo, sillones o camas.

Las personajes parecen intranquilas y vulnerables frente a la mirada de otro; sus expresiones faciales denotan temor y desconfianza, y sus vestimentas develan ciertas zonas desnudas del cuerpo, funcionando como "una arquitectura masturbatoria que 
FIGURA 3

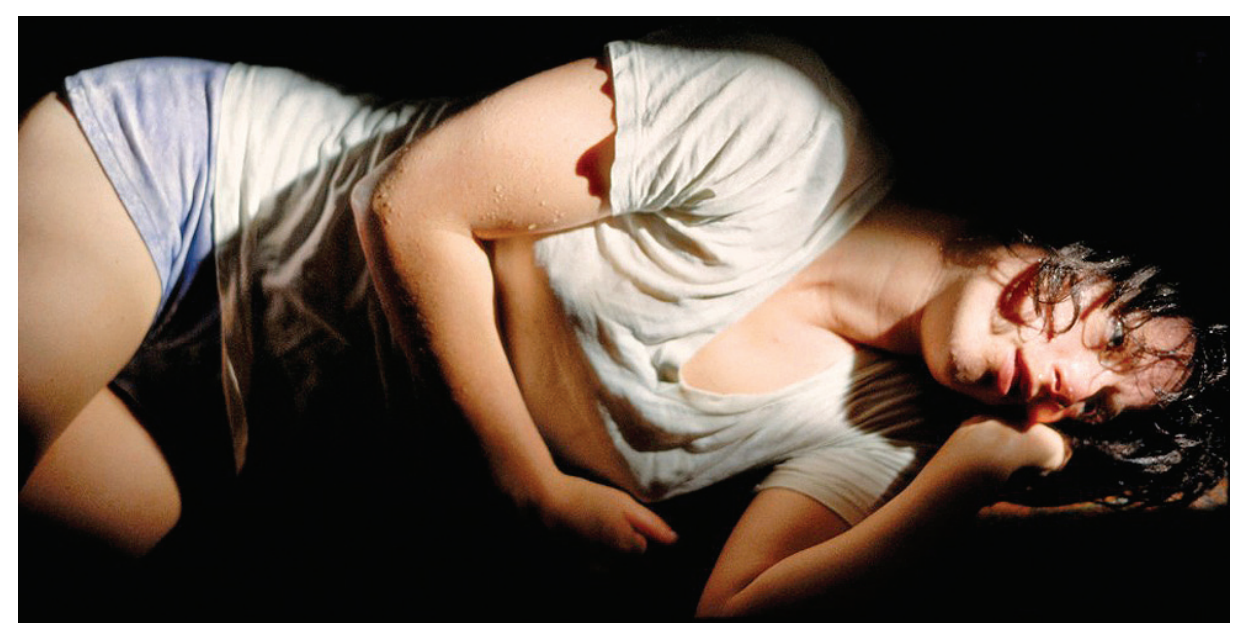

Untitled \# 86, Centerfolds, Cindy Sherman. Impresión cromogénica a color $61 \times 121.9 \mathrm{~cm}$. 1981. Obra de Eric Fischl y April Gornik.

al mismo tiempo lo oculta y lo desvela, lo cubre y lo expone" (Preciado, Pornotopía 76) (Untitled \#89, Untitled \#96, Untitled \#91, Untitled \#87); a su vez, muchas de las personajes intentan cubrirse con ropas y sábanas (Untitled \#95, Untitled \#93, Untitled \#87) o se cobijan a sí mismas en forma de ovillo, como intentando ocultarse de la mirada del otro (Untitled \#85, Untitled \#86, Untitled \#92, Untitled \#88). El formato de la imagen sugiere la pasividad y receptividad de lo horizontal, mujeres recostadas y sentadas que aparecen atravesadas por la verticalidad de la mirada del observador, lo que se manifiesta en la posición de la cámara muchas veces situada por encima de ellas, generando un plano picado (Untitled \#91, Untitled \#92, Untitled \#93, Untitled \#96), o desde una exterioridad graficada por la linealidad de la luz (Untitled \#85, Untitled \#86, Untitled \#87, Untitled \#94, Untitled \#95). Las imágenes se ven recortadas, fragmentadas; hay un resto y un exceso que no se registra, por lo que los límites corporales de las personajes son voluntariamente mutilados por el ojo de la cámara. Los tres aspectos formales -horizontalidad del formato, punto de vista de la cámara y marco de la fotografía- narran la violencia con que es invadida la intimidad de los cuerpos, que ya no son propios, sino construidos y delimitados por el otro como objeto de satisfacción voyeurística para el observador masculino, lugar en que también nos situamos nosotros mismos como observadores, así como la misma cámara de Cindy Sherman, quien es sujeto y objeto a la vez.

En el análisis de la película París en llamas (Jennie Livingston) que realiza en Cuerpos que importan, Judith Butler toma la revisión crítica que haría bell hooks ${ }^{7}$ del

$7 \quad$ Pseudónimo de Gloria Jean Watkins, quien toma del nombre de su abuela. Intencionalmente es escrito con minúsculas para distinguirse de ella, y con la intención de otorgarle valor a su trabajo y no a sí misma como autora. 
filme. La autora y activista cuestiona la postura de la directora y la identifica como una posición imperial omnisciente, que con el poder fálico de su mirada transformaría aquellos hombres gay marginados en mujeres para ser objeto de mirada de los espectadores. La cámara adquiere el valor de instrumento fálico que logra esta transformación, al igual que la cámara de Cindy Sherman que reproduce los estereotipos femeninos contemporáneos y la violencia de la mirada masculina, al imitarla y reiterarla compulsivamente, reiteración que caracteriza la época de la reproductibilidad técnica (Benjamin).

A partir de las conceptualizaciones de Butler, consideramos el género como una identidad no estable, que se construye socialmente en el tiempo mediante una "reiteración estilizada de actos" (El género 273) y otros medios discursivos, lo que le otorgaría una categoría pública con consecuencias políticas, al "preservar el género dentro de su marco binario" (273) y al legitimar la serie de significados determinados socialmente. Sería posible entonces considerar las reiteraciones de los actos fotográficos de Cindy Sherman como una operación que preserva los significados socialmente atribuidos a la mujer, por lo que paradójicamente restablece y legitima los estereotipos femeninos, así como las posiciones binarias de hombre masculino/activo/observador y de mujer femenina/pasiva/objeto de mirada. La ambivalente y contradictoria naturaleza de las fotos, que reproduce la violencia hacia la mujer, sería la razón por la que la editora de la revista Artforum habría rechazado su publicación. Sobre la característica posición de la mujer como objeto de mirada, John Berger comenta:

Los hombres actúan y las mujeres aparecen. Los hombres miran a las mujeres. Las mujeres se contemplan a sí mismas mientras son miradas. Esto determina no sólo la mayoría de las relaciones entre hombres y mujeres sino también la relación de las mujeres consigo mismas. El supervisor que lleva la mujer dentro de sí es masculino: la supervisada es femenina. De este modo se convierte a sí misma en un objeto, y particularmente en objeto virtual, en una visión (cit. en Pollock 78).

Para Haraway, la cámara sería uno de los artefactos protéticos que develan la inexistencia de una mirada pasiva, ya que permite evidenciar que "todos los ojos, incluidos los nuestros, son sistemas perceptivos activos que construyen traducciones y maneras de ver, es decir, formas de vida" (327). En tanto prótesis de la mirada masculina, la cámara fotográfica no solo reproduce estos cuerpos estereotípicos, sino que los produce. Siguiendo las conceptualizaciones de Preciado, las construcciones del género, el sexo y el cuerpo estarían insertas en un sistema más amplio en el que la tecnología ha intervenido activamente, por lo que el sexo sería una "tecnología de dominación heterosocial que reduce el cuerpo a zonas erógenas en función de una distribución asimétrica de poder entre los géneros (femenino/masculino)" (Manifiesto 22). En este caso, la mirada se ha vuelto un sentido altamente erotizado y masculinizado, el que encuentra un suplemento en la cámara fotográfica. Así como en la pornografía, la 
FIGURA 4

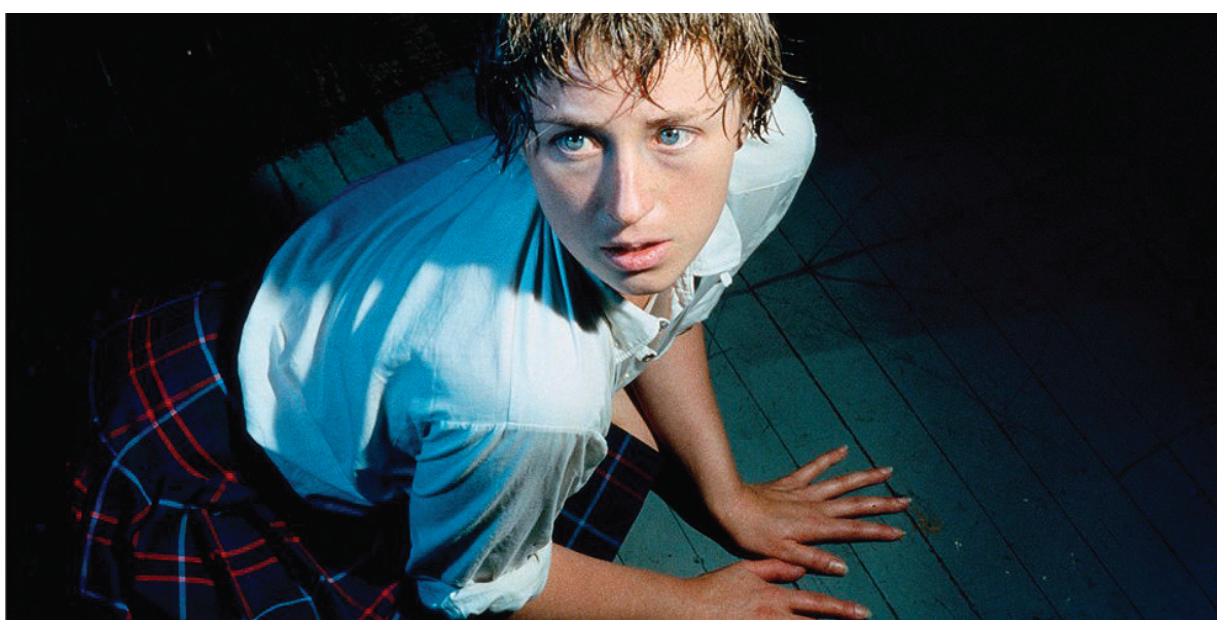

Untitled \#92, Centerfolds. Cindy Sherman. Impresión cromogénica a color $61 \times 121.9 \mathrm{~cm}$. 1981 . The Museum of Modern Art, New York. The Fellows of Photography Fund.

mirada y la subjetividad masculina dejan su huella en el efecto político de producir la representación:

(...) el verdadero centro de la representación pornográfica es precisamente el ojo (la mirada y la subjetividad) masculino, que paradójicamente nunca forma parte de la imagen. No obstante, el ojo masculino deja su marca -indicio de su poder de fabricar imágenes- para así completar el marco que ha tenido la sagacidad de abandonar justo antes de la toma fotográfica (Preciado, Pornotopía 69-70).

Podría decirse entonces que la posición subjetiva de Cindy Sherman, al ubicarse del lado de la cámara, sería la de supervisor masculino, la/el que ejerce esa violencia trasformadora sobre sí misma, convirtiéndose en un objeto virtual expuesto a su propia mirada y la de los otros, todas masculinas. Al igual que en los reportajes fotográficos de la revista Playboy, domina el placer masculino de mirar sin ser visto: "las imágenes situaban al lector en la posición del voyeur que, a través de una mirilla, una rendija o una ventana, lograba acceder a un espacio hasta entonces privado" (54). Esta rendija o ventana es sutilmente sugerida por la distribución de la luz, la que entra en un espacio cerrado y privado donde se encuentra la personaje (no pasa desapercibido el hecho de que el concepto de voyeur, para referirse al sujeto que obtiene placer sexual por medio de la mirada, se utilice en género masculino y escasamente en género femenino, voyeuse). ¿Qué posibilidades surgen para salir de este circuito reiterativo? Según la opinión de Butler, para generar un efecto transformador del género es necesario crear una relación arbitraria entre los actos, en una "de-formidad o una repetición paródica que demuestra que el efecto fantasmático de la identidad constante es una construcción políticamente insuficiente" (El género 274); de ahí que la parodia del género 
constituya una posibilidad subversiva que encarnarían particularmente el travestismo y las identidades lesbianas butch/femme, ya que actuarían una discontinuidad entre lo que Butler sitúa como las tres dimensiones contingentes de la corporalidad: el sexo anatómico, la identidad del género y la actuación del género. La parodia produciría una visión del sexo y el género como desnaturalizados mediante su actuación paródica repetitiva, generando un efecto disonante. En el caso de la obra Centerfolds de Cindy Sherman, sería posible revertir el efecto de perpetuar los estereotipos femeninos al considerarla una parodia que reproduce estereotipos de género y su violencia asociada, pero cuestionándola en un acto subversivo. Sin embargo, consideramos que no se acercaría tanto a la noción de parodia del género, por el hecho de ser ella misma una mujer y realizar personificaciones de la feminidad contemporánea, lo que no generaría la discontinuidad sexo/género de la que habla Butler. Pensamos que un concepto que nos aproxima mayormente a la imitación irónica de Sherman es el de pastiche, ya que posee más cercanía con el ámbito del arte contemporáneo y nos permite diferenciarlo de la parodia performática del travestismo.

La noción de parodia del género que Butler expone, como ya se mencionó, no supone que exista un original imitado, ya que ello implicaría una anterioridad ontológica, un origen que podría ser objeto de imitación, sino que la parodia "es de la noción misma de un original" (El género 269). Tomando las elaboraciones que Fredric Jameson realiza en "Posmodernismo y sociedad de consumo", Butler comenta que la imitación irónica que se burla de la noción de un original sería más propia del pastiche que de la parodia. Jameson utiliza la literatura para diferenciar estos conceptos, y refiere que ambos se caracterizan por recurrir a la imitación y la mímica de otros estilos; sin embargo, en el caso de la parodia se supone un estilo único anterior al que se imita, que es inequívoco y generalmente característico de un autor. En tal caso, la parodia "se aprovecha del carácter único de estos estilos y se apodera de sus idiosincrasias y excentricidades para producir una imitación que se burla del original" (Jameson, "Posmodernismo" 168-9), por lo que supondría la existencia de una norma que se imita. Al contrario, el pastiche se generaría en el contexto del cuestionamiento posmoderno de la noción de norma lingüística, en que a partir de la fragmentación y privatización de la lengua, se produciría la muerte de los grandes metalenguajes y relatos, asociados a la muerte del autor y del individualismo: "la desaparición del sujeto individual, y su consecuencia formal, el desvanecimiento progresivo del estilo personal, han engendrado la actual práctica casi universal de lo que podríamos llamar el pastiche" (Jameson, El posmodernismo 41). Para el autor, entonces, aunque el pastiche es una práctica presente ya en la modernidad, es en la posmodernidad cuando se le otorgan sus más potentes condiciones de producción, debido al capitalismo tardío, la muerte del sujeto y de los grandes metarrelatos, así como a la creciente innovación estilística, por lo que "todo lo que queda es imitar estilos muertos, hablar a través de máscaras y con las voces de los estilos en el museo imaginario" (Jameson, "Posmodernismo" 171-2, el énfasis es nuestro). El pastiche 
aparece para ridiculizar estos estilos muertos, a partir de la certeza de la inexistencia de una norma y un original al cual imitar:

El pastiche, como la parodia, es la imitación de un estilo peculiar o único, llevar una máscara estilística, hablar en un lenguaje muerto: pero es una práctica neutral de esa mímica, sin el motivo ulterior de la parodia, sin el impulso satírico, sin risa, sin ese sentimiento todavía latente de que existe algo normal en comparación con lo cual aquello que se imita es bastante cómico. El pastiche es parodia neutra, parodia que ha perdido su sentido del humor (170).

La inexistencia de un original del cual burlarse le quita el “impulso satírico", la risa de la imitación de ese estilo peculiar; sin embargo, "la pérdida del sentido de «lo normal» puede ser su propio motivo de risa, sobre todo cuando «lo normal», «lo original», resulta ser una copia, y una copia inevitablemente fallida, un ideal que nadie puede personificar" (Butler, El género 270). Entonces la burla aparece con la certeza de que la idea de un original fue siempre algo derivado.

Consideramos que para el análisis de los actos fotográficos de la obra Centerfolds, el concepto de pastiche permite distanciarse de la parodia performática del travestismo, por tratarse de actos que cuestionan la existencia de un original en torno a la mujer y la feminidad. El pastiche de Sherman permitiría un efecto subversivo al actuar una burla de la idea de una identidad ontológica y de un ideal de feminidad, pero no dentro de una narrativa de discontinuidad entre sexo y género que cuestiona la heteronormatividad, como en el caso del travestismo, sino en un acto que una persona de sexo femenino realiza sobre el género femenino, corporeizando un gesto de una copia mal hecha de la feminidad, lo que daría cuenta de un revuelta subversiva al no requerir de un sexo específico para generar el efecto desnaturalizado del género. Las personajes de Sherman parecen mujeres siendo ultrajadas por su extrema vulnerabilidad -por lo que podrían ser parte de una revista masculina-, pero como personajes de un softcore mal hecho, afirma Mulvey: "le dan un fuerte sentido de pastiche soft-core" (142). Una copia - pastiche- en evidencia, mediante una exhibición hiperbólica del modelo, con una exaltación de rasgos estereotípicos como posturas, miradas que serían propias de la mujer y la presencia de elementos que evidencian un disfraz, como lo es una vestimenta característica, el pelo que no oculta ser una peluca y los rostros que dan la sensación de una máscara -Mulvey comenta: "dado que Sherman utiliza cosméticos literalmente como una máscara es que hace visible lo femenino como una mascarada" (142, el énfasis es nuestro), escenificando un juego de palabras entre "mask" y "makes" que se asimila al "make up" del maquillarse-. Máscara y disfraz, construcciones que requieren de prótesis y prolongaciones externas para el

8 "...they give a strong sense of soft-core pastiche".

9 "because Sherman uses cosmetics literally as a mask she makes visible the feminine as masquerade". 


\section{FIGURA 5}

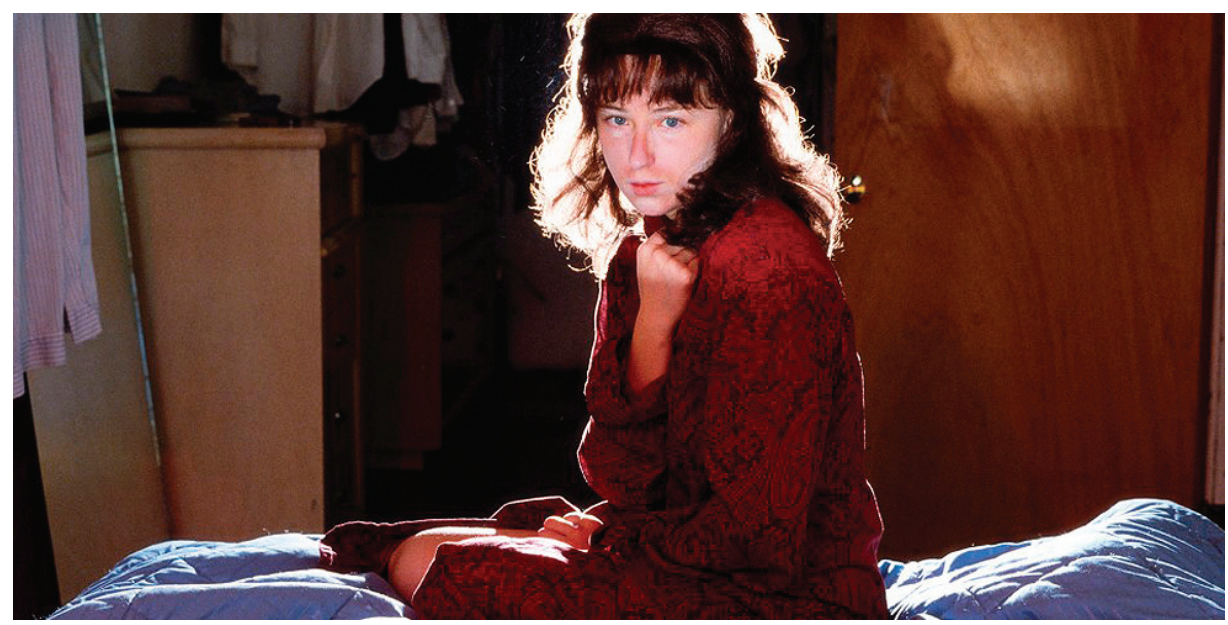

Untitled \# 85, Centerfolds, Cindy Sherman. Impresión cromogénica a color $61 \times 121.9 \mathrm{~cm} .1981$. Colección de Jean Pigozzi, Ginebra.

montaje de la identidad, un simulacro de la identidad que se evidencia por medio del pastiche y el error, la hiancia que da cuenta del disfraz y de la no clausura del sujeto como estrategias subversivas de la identidad.

\section{Conclusiones}

Consideramos que la obra Centerfolds de la artista norteamericana Cindy Sherman contribuye a los discursos descentralizadores de las nociones de identidad y de género, por medio de una puesta en escena subversiva que permite graficar el carácter performativo del género, así como los estereotipos de género de la mujer producidos y perpetuados por el discurso hegemónico y por los mass media. Las personificaciones de la artista tendrían un efecto similar al de la parodia del género propuesta por Judith Butler para las expresiones del transformismo y las identidades butch/femme en las relaciones lesbianas, al tratarse de una imitación burlesca que contribuye a una desnaturalización del sexo y el género a través de una estrategia de desmontaje de la identidad. Sin embargo, como vimos, la noción de pastiche (Jameson) resulta mayormente provechosa para abordar una crítica a la noción misma de un original, dentro del contexto de una producción de arte contemporáneo. Proponemos que las personificaciones escenificadas por Cindy Sherman darían cuenta de una imitación fallida, un simulacro, una mala copia - pastiche- y disfraz de figuras de la feminidad contemporánea, personificaciones que reflejan el fracaso de la imagen estable y sustancialista de la identidad, y revelan los ideales de mujer producidos por los discursos dominantes. A su vez, las fotografías dan cuenta de la posición de la mujer como femenina/pasiva/objeto de mirada, frente al 
observador masculino/activo/voyeur que se ubica en la posición violenta del supervisor que goza de la vulnerabilidad femenina. Desde este punto de vista, a partir de algunas nociones de Berger y Preciado, problematizamos nuestra posición de observadores, al igual que la cámara de la misma Cindy Sherman, dado que al reproducir este acto perpetuaría la violencia cuestionada y nos obligaría a una toma de posición en la que nos hagamos parte de la estrategia subversiva.

El efecto subversivo de la parodia -en este caso, del pastiche-, según Butler, no sería siempre posible, para ello es necesario "implicar a sus espectadores en el acto" (Cuerpos 199): se requiere de una audiencia que no se aparte, no potencie estas imágenes como ideales de género y que sea capaz de ver la ironía en ellas. Sobre esto, la misma Cindy Sherman comenta: "En un comienzo sentí que algo de mi trabajo fue erróneamente percibido por las feministas, quienes no entendieron la ironía. Hablo de las fotografías Centerfolds"10 (“Cindy Sherman" párr. 6). Entonces, según esta perspectiva, para que la obra de Cindy Sherman surta efecto, se requiere de un espectador atento, que suponga esta crítica de la noción de un original y no potencie las imágenes de la mujer representadas como ideales de género. Pero ¿es siempre posible considerar una audiencia que advierta la crítica y la ironía en ellas para evitar la perpetuación de los estereotipos? Y por otro lado, ¿el hecho de que el acto subversivo se genere dentro del mismo discurso del cual nace la construcción de identidades enajenantes, como efecto de este mismo, no habla de una imposibilidad de salir de esta lógica? Según Butler, no habría una imposibilidad, dado que el género sería siempre un simulacro: "Los géneros no pueden ser verdaderos ni falsos, ni reales ni aparentes, ni originales ni derivados. No obstante, como portadores creíbles de esos atributos, los géneros también pueden volverse total y radicalmente increíbles” (El género 275).

\section{Referencias}

Barthes, Roland. Fragmentos de un discurso amoroso. Buenos Aires: Siglo xxI, 2004. Impreso.

Benjamin, Walter. "La obra de arte en la época de su reproductibilidad técnica". Discursos Interrumpidos. Madrid: Taurus, 1973. 14-57. Impreso.

Burton, Johanna. Cindy Sherman. October Files. Cambridge: MIT Press, 2006. Impreso. Butler, Judith. El género en disputa. Buenos Aires: Paidós, 2007. Impreso.

---. Cuerpos que importan. Sobre los limites materiales y discursivos del «sexo». Buenos Aires: Paidós, 2008. Impreso.

Cotton, Charlotte. The photograph as contemporary art. London: Thames \& Hudson, 2004. Impreso.

10 "Early on I felt that some of my work was wrongly perceived by feminists, who didn't get the irony. I'm talking about the Centerfolds pictures". 
Derrida, Jacques. "La estructura, el signo y el juego en el discurso de la ciencias humanas”. Escritura y la Diferencia. Barcelona: Anthropos, 1989. 383-401. Impreso.

Ferrater Mora, José. Diccionario de filosofía abreviado. Buenos Aires: Sudamericana, 2008. Impreso.

Foster, Hal. El retorno de lo real. La vanguardia a finales de siglo. Madrid: Akal, 2001. Impreso.

Freud, Sigmund. "Algunas consecuencias psíquicas de las diferencias anatómicas entre los sexos". Obras Completas, vol. xIx. Buenos Aires: Amorrortu, 1992. 259-276. Impreso.

Guillerault, Gérard. Le miroir et la psyché: Dolto, Lacan et le stade du miroir. Paris: Gallimard, 2003. Impreso.

Haraway, Donna J. Ciencia, cyborgs y mujeres. La reinvención de la naturaleza. Madrid: Cátedra, 1995. Impreso.

Jameson, Fredric. El posmodernismo o la lógica cultural del capitalismo avanzado. Buenos Aires: Paidós, 1991. Impreso.

---. "Posmodernismo y sociedad de consumo". La posmodernidad. Barcelona: Kairós, 2006. 165-187. Impreso.

Jiménez, Marc. La querella del arte contemporáneo. Buenos Aires: Amorrortu, 2010. Impreso.

Lacan, Jacques. "El estadio del espejo como formador de la función del yo (je) tal como se nos revela en la experiencia psicoanalítica”. Escritos 1. Buenos Aires: Siglo xxI, 2003. 86-93. Impreso.

Laplanche, Jean y Jean-Bertrand Pontalis. Diccionario de psicoanálisis. Buenos Aires: Paidós, 2001. Impreso.

Mulvey, Laura. "A phantasmagoria of the female body: the work of Cindy Sherman". New Left Review 1.188 (1991). <https://newleftreview.org/I/188/laura-mulveya-phantasmagoria-of-the-female-body-the-work-of-cindy-sherman $>$ Web. Mayo 2013.

Paris is burning. Dir. Jennie Livingston. Act. André Christian, Dorian Corey y Paris Duprée. Miramax Films, 1990. Fílmico.

Pollock, Griselda. Encuentros en el museo feminista virtual. Madrid: Cátedra, 2010. Impreso.

Preciado, Beatriz. Manifiesto contra-sexual. Prácticas subversivas de identidad sexual. Madrid: Ópera Prima, 2002. Impreso.

---. Pornotopía. Arquitectura y sexualidad en «Playboy» durante la guerra fría. Madrid: Anagrama, 2010. Impreso.

Richard, Nelly. Feminismo, género y diferencia(s). Santiago: Palinodia, 2008. Impreso. Sherman, Cindy. Centerfolds. 1981. Fotografías $61 \times 121.9 \mathrm{~cm}$. Cindy Sherman Restrospective. Curadora Eva Respini. Museum of Modern Art, New York (MOMA). <http://www.moma.org/interactives/exhibitions/2012/cindysherman>. Web. Mayo 2013. 
--.. "A portraitist's romp through art history". Entr. Glenn Collins. The New York Times [New York, UsA]. 1 Feb. 1990: s.p. <www.nytimes.com/1990/02/01/arts/aportraitist-s-romp-through-art-history.html>. Web. Mayo 2013.

---. "Cindy Sherman". Entr. Linda Yablonsky. The Wall Street Journal [New York, USA]. 23 Feb. 2012: s.p. <http://online.wsj.com/article/SB1000142405297020479530 4577221334054364196.html>. Web. Jun. 2013.

Recibido: 16 junio 2014 Aceptado: 13 agosto 2015 